\title{
Experiencia de producción de lechuga americana (Lactuca sativa) hidropónica, tipo NFT
}

\author{
Lettuce (Lactuca sativa) production \\ in a NFT hydroponic system
}

Laura Brenes-Peralta'

María Fernanda Jiménez-Morales ${ }^{2}$

Fecha de recepción: 12 de junio del 2013

Fecha de aprobación: 06 de noviembre del 2013

Brenes-Peralta, L; Jiménez-Morales, M. Experiencia de producción de lechuga americana (Lactuca sativa) hidropónica, tipo NFT. Tecnología en Marcha. VI Encuentro de Investigación y Extensión. Pág 56-64.

I Docente e investigadora. Escuela de Agronegocios Instituto Tecnológico de Costa Rica. Costa Rica. Ingeniera Agropecuaria Administradora con Énfasis en Empresas Agropecuarias, Máster en Gerencia y Gestión Ambiental. Teléfono: (506)2550-2287. Correo electrónico: labrenes@itcr.ac.cr.

2 Docente e investigadora. Escuela de Agronegocios. Instituto Tecnológico de Costa Rica. Costa Rica. Ingeniera Agropecuaria Administradora con énfasis en Empresas Agropecuarias, Máster en Sistemas Modernos de Manufactura. Teléfono: (506)25502287. Correo electrónico: maria.jimenez@itcr.ac.cr 


\section{Palabras claves}

Hidroponía; Nft; Lechuga; Protocolo de manejo de cultivo.

\section{Resumen}

El término hidroponía se concibe como el estudio de los cultivos sin tierra. En la actualidad, es explotada comercialmente, y al cultivo se le agrega una solución nutriente que contiene los elementos esenciales requeridos por la planta para su crecimiento, bajo distintas técnicas, como la de Cultivo con Flujo Laminar de Nutrientes o NFT, por sus siglas en inglés.

En el Centro de Prácticas Docentes e Investigación Agropecuaria de la Escuela de Agronegocios del Instituto Tecnológico de Costa Rica (TEC) se cuenta, actualmente, con un sistema de este tipo NFI donde estableció una actividad de fortalecimiento que ha resultado en la observación de ciertas características a partir de la experiencia generada, de la cual se espera fomentar el uso de la hidroponía, así como divulgar información técnica y de buenas prácticas en este tipo de cultivo entre usuarios interesados.

\section{Key words}

Hydroponics; nft; lettuce; agriculture and produce management protocole.

\begin{abstract}
Abstrat
Hydroponics is considered to be the study of plant growth in the absence of soil. Nowadays it is used with commercial purposes in which different plants are set in an environment where a nutrient solution is added so that the plant can grow. NFT is a kind of hydroponic agriculture, that means Nutrient Film Tecnique. There is an established NFT system at the Centro de Prácticas Docentes e Investigación Agropecuaria, from the Agribusiness School at Instituto Tecnológico de Costa Rica. Therefore a research project was started in 2013, to promote this type of Agriculture, and create an experience that resulted in technical and Good Practices information to be delivered and shared with interested beneficiaries.
\end{abstract}

\section{Introducción}

El término hidroponía se genera de dos palabras griegas, hydro (agua) y ponos (labor o trabajo), la unión de estas palabras significa trabajar en el agua. La hidroponía puede definirse, entonces, como la ciencia del cultivo de plantas sin uso de tierra, en un medio inerte, al cual se le agrega una solución nutriente que contiene todos los elementos esenciales requeridos por la planta para su crecimiento normal (Barbado, 2005).

La técnica hidropónica de Cultivo con Flujo Laminar de Nutrientes, conocida como NFT (Nutrient Film Technique), tiene sus orígenes en Inglaterra. Durante la década de los años sesentas se desarrolló este sistema para aumentar la productividad del sector de producción hidropónica. El método sufrió modificaciones en la Universidad de la Molina en Perú, donde se propuso utilizar tubos de PVC con perforaciones donde se colocan las plantas de lechuga, en unidades de producción de 10 tubos, separados de $20 \mathrm{~cm}$ a $25 \mathrm{~cm}$. Adicionalmente, se utiliza una bomba de acero inoxidable para la inyección de la solución nutritiva a presión, la cual entra por un extremo de los tubos y se recolecta al final de estos, para retornar al tanque de almacenamiento. Este ciclo permite la reutilización de los nutrientes, para un mayor aprovechamiento del recurso favoreciendo la absorción en los sistemas radiculares (González, 2008).

La Escuela de Agronegocios del TEC, valorando tendencias productivas actuales y de mercado, consideró insertar en sus actividades de fortalecimiento la propuesta llamada Modelo de manejo de un sistema de producción de hortalizas de hoja bajo la modalidad de hidroponía NFT. Como objetivo general se planteó: "Definir un modelo de manejo de un sistema de producción de hortalizas de hoja bajo la modalidad de hidroponía NFT, en 
el Centro de Prácticas Docentes e Investigación Agropecuaria, con miras a generar experiencias e información técnica en este Centro".

La experiencia generada ha podido ser observada por estudiantes, funcionarios, investigadores, comunidad en general, quienes podrían eventualmente estar interesados en incursionar en actividades productivas que generen un producto libre de algunas plagas y enfermedades, y con un eficiente uso del espacio, los fertilizantes, y el tiempo.

Adicionalmente, se ha percibido que en el mercado costarricense existen consumidores que están dispuestos a pagar un precio más alto por productos de origen hidropónico, según fue posible corroborar en la oferta de ciertas cadenas de supermercados (Brenes, 20l0).

La actividad propuesta inició labores formalmente en febrero 2013 en el invernadero del Centro de Prácticas Docentes e Investigación Agropecuaria de la Escuela de Agronegocios, tras varios ensayos previos a la actividad, en el 2012 .

\section{Materiales y metodología}

La actividad se desarrolló en el sistema de hidroponía NFT ubicado en el invernadero del Campo de Prácticas de la Escuela de Agronegocios del TEC. El sistema tiene cubierta de plástico y paredes antiáfidos, con una cámara de ingreso donde se ubica un pediluvio y un aspersor con desinfectante, ambos con una solución de Vanodine ( $\mathrm{F}$ FM. Además, tiene implementada una cobertura interna de sarán para manejo de la temperatura interna del invernadero, y un medidor de $\mathrm{CO}_{2}$, temperatura y humedad relativa.

Del sistema instalado en el invernadero, se utilizaron dos camas de cinco tubos cada una.

Los tubos son de PVC blanco, de 4" de diámetro y $6 \mathrm{~m}$ largo, con 113 aperturas para la inserción de las canastillas las que se colocan las plantas. Además, el sistema cuenta con un reservorio con aislante térmico, mecanismo de recirculación y un sistema de bombeo automatizado que consiste de una bomba y un timer que se programa para el arranque y apagado de esta. La integración del sistema se puede observar en la figura $I$.

Las canastillas usadas en este tipo de sistema hidropónico usualmente son adquiridas de proveedores locales, como las que se observan en la figura 2; sin embargo, también se valoró la reutilización de un material como son los vasos plásticos o desechables, a los que se les realizaron ranuras, como se puede ver en la figura 3.

Una vez activado el sistema, se utilizaron soluciones nutritivas tipo $A$ y $B$, descritas brevemente en el cuadro 1.

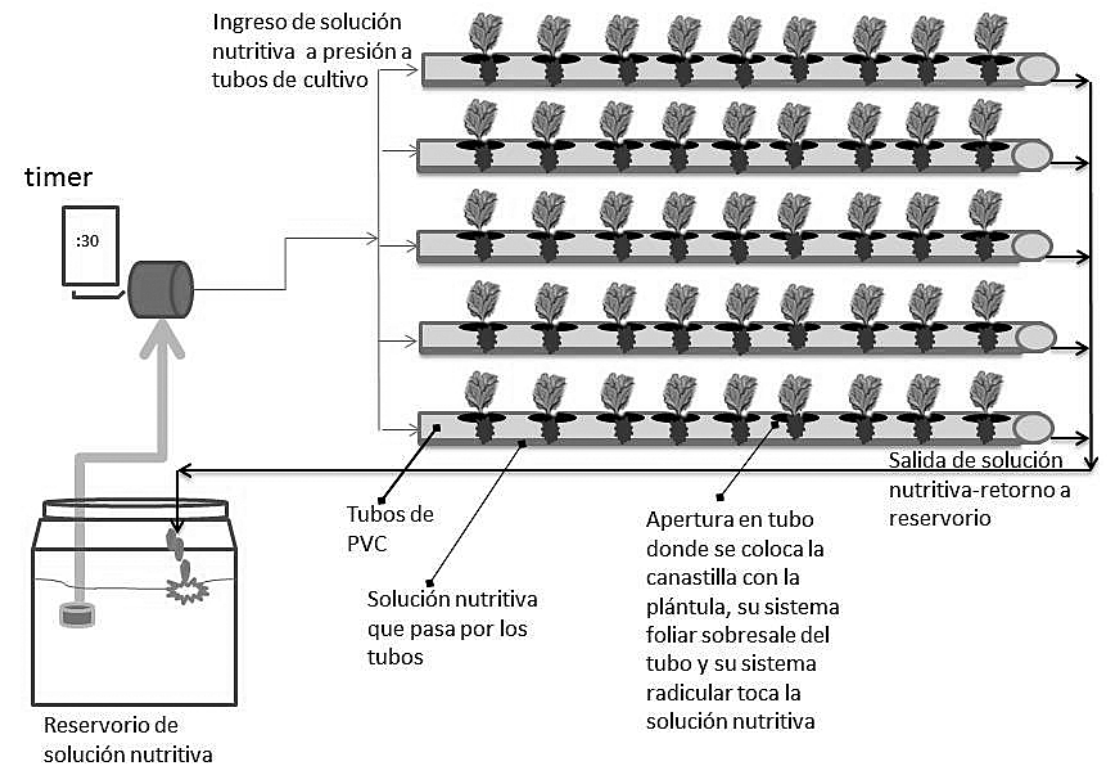

Figura I. Diagrama de sistema NFT (no a escala). Fuente: las autoras, 20।3 
Durante el 2012, se realizaron algunas pruebas piloto para familiarizarse con el funcionamiento del sistema, así como algunos ajustes básicos sobre tiempos de circulación, nivelación de camas, y concentración de soluciones. Durante el 2013, se realizaron 5 ensayos con lechuga americana variedad Sargasso (Lactuca sativa var. Capitata), donde se valoró el uso de distintos tipos de almácigo, tipos de canastillas, tiempos de recirculación, formulaciones de soluciones nutritivas y tratamientos de control de enfermedades.

Se definió cosechar a las 7 semanas después del trasplante.

Como resultados, se analizaron las variaciones entre un ensayo y otro en términos de tamaño y peso de las hortalizas, y apariencia de la planta, principalmente.

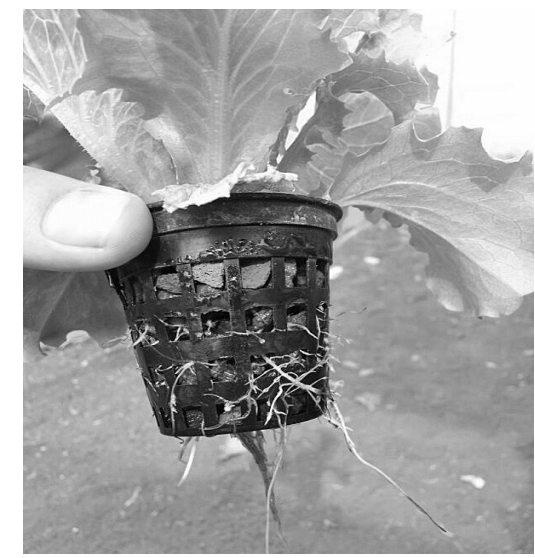

Figura 2. Canastillas para NFT adquiridas de proveedor local. Fuente: (Gómez Coto y Sáenz Guevara, 2013).

Cuadro I. Soluciones nutritivas empleadas en los ensayos
Por motivos del estado de la actividad de fortalecimiento al momento de presentación de este artículo, los ensayos estadísticos no han culminado, por lo que se hizo solamente una descripción cualitativa de la experiencia que se pudo obtener con la observación del proceso del desarrollo de los ensayos estadísticos.

\section{Resultados y discusión}

Según la observación del proceso de los ensayos, fue posible determinar que es vital la incorporación de protocolos de siembra, control y cosecha, los cuales se describen a continuación.

\section{Protocolo de siembra}

\section{Limpieza del sistema de hidroponía}

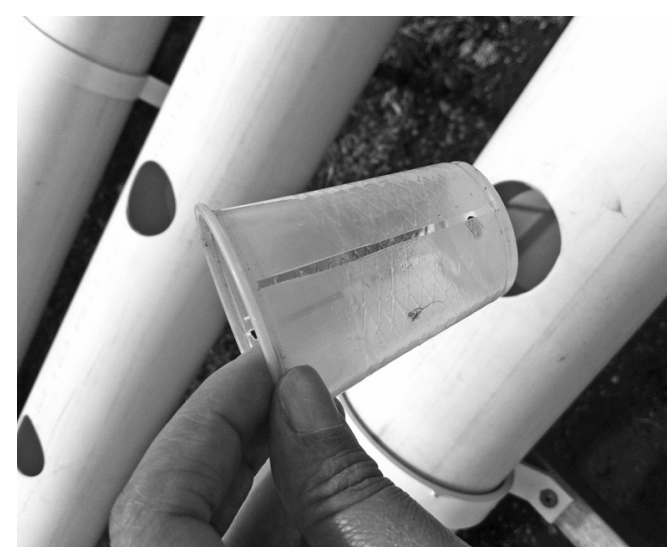

Figura 3. Canastillas para NFT hechas de vasos desechables con ranuras. Fuente: las autoras, 2013.

\begin{tabular}{|c|c|}
\hline Solución madre A & Solución madre B \\
\hline $\begin{array}{l}\text { Fosfato Monoamónico ( } 12-60-0) \\
\qquad 340 \mathrm{~g} / \mathrm{l} 0 \text { I de agua }\end{array}$ & $\begin{array}{l}\text { Sulfato de Magnesio } \\
220 \mathrm{~g} / 2 \text { I de agua }\end{array}$ \\
\hline $\begin{array}{l}\text { Nitrato de Calcio } \\
2080 \mathrm{~g} / 10 \text { I de agua }\end{array}$ & $\begin{array}{l}\text { Metalosato de Hierro } \\
12 \mathrm{ml} / 2 \text { I de agua }\end{array}$ \\
\hline $\begin{array}{l}\text { Nitrato de Potasio } \\
\text { | } 100 \mathrm{~g} / \mathrm{l} 0 \text { | de agua }\end{array}$ & $\begin{array}{l}\text { Nutrientes menores (Fetrilon Combi | }(\text { ) } \\
\qquad 12 \mathrm{~g} / 2 \text { I de agua }\end{array}$ \\
\hline & $\begin{array}{l}\text { Ácido Bórico } \\
1.2 \mathrm{~g} / 2 \text { | de agua }\end{array}$ \\
\hline
\end{tabular}

Fuente: (Gómez Coto y Sáenz Guevara, 2013) citando a Ing. Luis Fernando Campos Meléndez con datos del INA y la Molina (201 I). 
Este proceso inicia 7 días antes de la siembra del producto, e incluye:

- Lavado exhaustivo con jabón y sacos que atraviesan de un extremo a otro cada uno de los tubos. Esta acción se repite dos veces, con el fin de eliminar cualquier tipo de contaminación del sistema.

- Llenado del tanque con 500 litros de agua, aproximadamente y circulación del sistema durante dos días con peróxido de hidrógeno al $3 \%$. Se incluye el ajuste del timer con el fin de hacerlo circular 30 minutos y reposar 30 minutos. Esta parte concluye con la eliminación de esta solución de tubos y tanque.

- Llenado del tanque con 500 litros de agua aproximadamente con 4 galones de cloro al 5\%, ajuste del timer con el fin de hacerlo circular 30 minutos y reposar 30 minutos durante 3 días para desinfectar internamente las tuberías.

- Liberación de los fluidos de desinfección del sistema y nuevo lavado con agua. Llenado de tanque a capacidad de siembra para permanecer listo al día siguiente inmediato para el trasplante.

\section{Preparación de sales nutritivas con}

las siguientes formulaciones

Mientras se está en el proceso de desinfección de tubos, se procede a la preparación de soluciones madre según la proporción de agua del sistema en el que se vaya a aplicar. En dos recipientes limpios y debidamente desinfectados se vierten las soluciones madres $A$ y $B$, en orden respectivo según se citan los ingredientes posteriormente hasta que estén totalmente disueltas en la proporción de agua indicada.

En este caso, por el sistema con el que se trabajó en estos ensayos, la composición de las soluciones fue la siguiente:

\section{Solución A}

- Fosfato Monoamónico (12-60-0) : I70 gramos

- Nitrato de Calcio: 1040 gramos

- Nitrato de Potasio: 550 gramos

Los pasos incluyeron:

- Medición de 3 litros de agua y vertido en un recipiente plástico que luego se pueda tapar, preferiblemente opaco.
- Adición, una por una, en el orden descrito de cada una de las sales nutricionales mencionadas.

- Adición de agua hasta completar un volumen de 6 litros y agitación durante 10 minutos hasta disolver por completo las sales.

\section{Solución B}

- Sulfato de Magnesio: I 10 gramos

- Metalosato de Hierro: 6 cc (equivalente a 4 gr de Quelato de Hierro)

- Fetrilon Combi 1:6 gramos

- Ácido Bórico (Borosil): 0.6 gramos

Los pasos incluyeron:

- Medición de 0,5 litros de agua y vertido en un recipiente plástico que, luego, se pueda tapar, preferiblemente opaco.

- Adición, una por una, en el orden descrito anteriormente, de cada una de las sales nutricionales mencionadas

- Adición de agua hasta completar un volumen de I litro y agitación durante 10 minutos hasta disolver por completo las sales

- Las soluciones preparadas se envasan y guardan en un lugar fresco y seguro, donde no tengan contacto directo con la luz del sol.

\section{Compra de almácigo}

El almácigo se compra en un establecimiento que cumpla las normas básicas de producción para evitar problemas en el sistema, lo que ha resultado a la fecha en la adquisición de almácigos de las variedades:

- Lechuga americana variedad Sargasso, con sustrato compuesto por peat moss.

- Lechuga americana variedad Sargasso, con sustrato compuesto de carbón de granza de arroz, granza de arroz.

Los almácigos se transportan cuidadosamente para evitar daños en las plántulas y en horas frescas para evitar deshidratación y estrés por calor.

\section{Trasplante}

Respecto a las operaciones del trasplante, se siguieron los siguientes pasos:

- Inmersión de raíces en una solución de peróxido 
de hidrógeno al $1 \%$ por I minuto las plantas. Igualmente, se da la inmersión de la piedra volcánica que servirá como sustrato para la planta, y de las canastillas por cinco minutos las piedras volcánicas para su desinfección en una solución de peróxido de hidrógeno al $1 \%$.

- Colocación de cada planta junto con unidades de piedra volcánica en las canastas destinadas para la siembra, tal y como se muestra en la figura 2.

- Activación del sistema NFT con un tiempo de circulación de agua de 15 min encendido y 45 min apagado por 24 horas.

- Al cumplir las 24 horas de circulación con agua se da la incorporación de las soluciones nutritivas en la proporción correspondiente al volumen total del agua circulante en el sistema: 2.5 cc de la solución A litro agua y I cc de la solución B/ litro agua.

- Ajuste de tiempos de recirculación de 30 minutos encendido contra 30 minutos apagado.

Protocolo de seguimiento y control del cultivo

Entrada al invernadero

Según las buenas prácticas agrícolas, para el ingreso al invernadero de las personas autorizadas se procede a abrir la puerta I entrar y cerrar la puerta I, se desinfectan las manos y los zapatos con la solución descrita anteriormente. Luego, se procede a abrir la puerta 2 entrar y cerrar la puerta 2 del invernadero.

\section{Labores de control y monitoreo}

Los primeros días de cada semana (lunes, en este caso) se da la adición de cloro al 0,05\% al sistema de circulación para tener limpieza preventiva durante todo el proceso de productivo.

Diariamente (de lunes a viernes en estos ensayos) se procede a un monitoreo del sistema en el que se revisa la estabilidad del ambiente interno del invernadero midiendo: humedad relativa (\%), temperatura $\left({ }^{\circ} \mathrm{C}\right)$, y concentración $\mathrm{CO}_{2}$ (ppm).

Igualmente, se procede a la medición de temperatura $\left({ }^{\circ} \mathrm{C}\right)$, conductividad (ms) y acidez de la solución $(\mathrm{pH})$ de la solución nutritiva recirculante en el sistema, y se procede a la corrección de estos factores en caso de ser necesario.
La observación del sistema en general y del estado físico de las plantas se realiza a diario también, y en el caso que se encuentre alguna lesión aparente, se procede a retirarla del sistema de producción para prevenir contaminación de todo el sistema.

Estas labores se realizan durante todo el proceso productivo, hasta el día de la cosecha.

\section{Protocolo de cosecha}

La cosecha de la lechuga se realiza a los 49 días de que esta fue trasplantada y las actividades incluyen:

- Retiro de plantas del sistema y colocación en cajones plásticos limpios.

- Traslado a un espacio cómodo y limpio para realizar las siguientes labores: retiro de la canastilla y piedra volcánica donde se encuentra sostenida la lechuga (figura 4), corte de la raíz (figura 5), pesado de la lechuga (figura 6), medición del diámetro de la planta (figura 7).

La importancia de estas labores radica en que todos los datos arrojados son los que indican el rendimiento de producción del sistema y nos permite conocer la eficiencia de éste.

La aplicación o no de elementos de cada protocolo resultó en diferencias en los ensayos documentados a la fecha (aunque aún no tratados estadísticamente), que mostraron los comportamientos descritos en el cuadro 2.

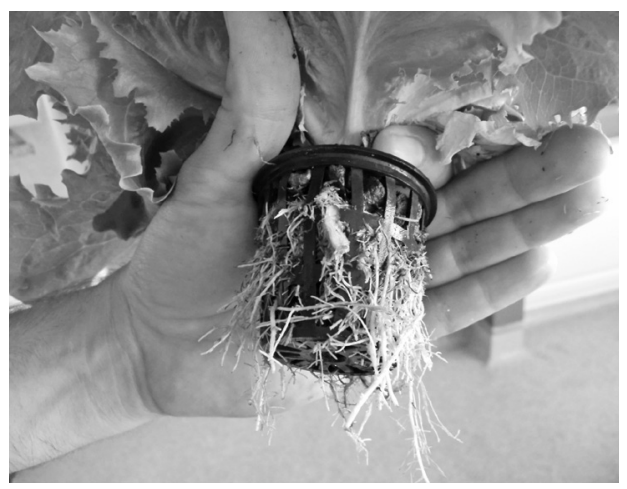

Figura 4. Retiro de Canastilla. Fuente: las autoras, 2013. 


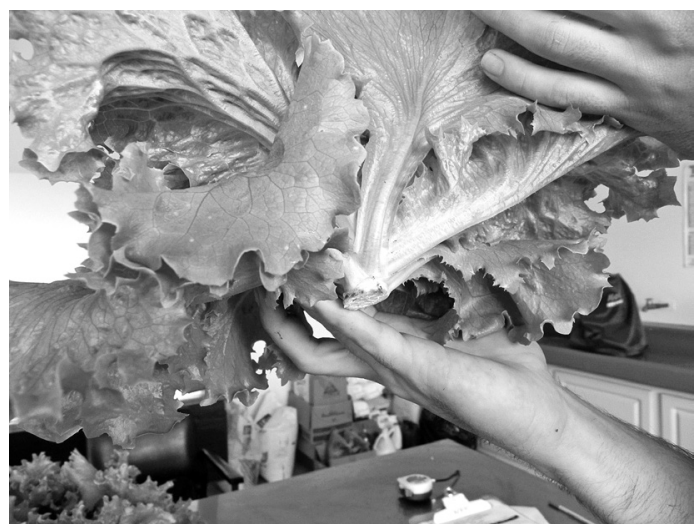

Figura 5. Corte de la raíz. Fuente: las autoras, 2013.

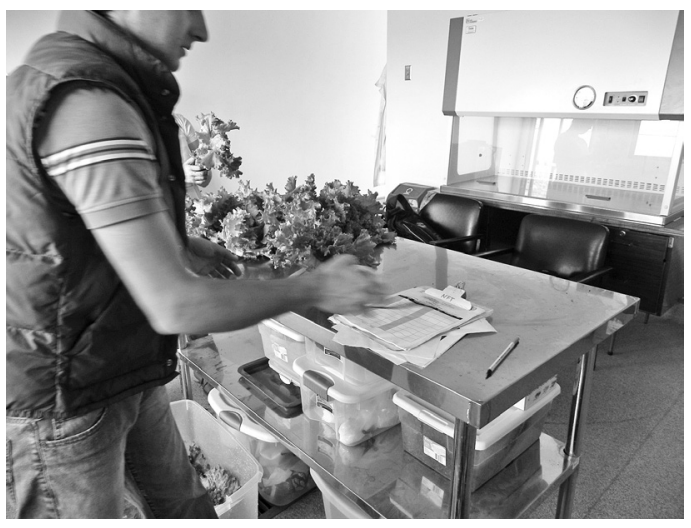

Figura 6. Pesado de la lechuga. Fuente: las autoras.

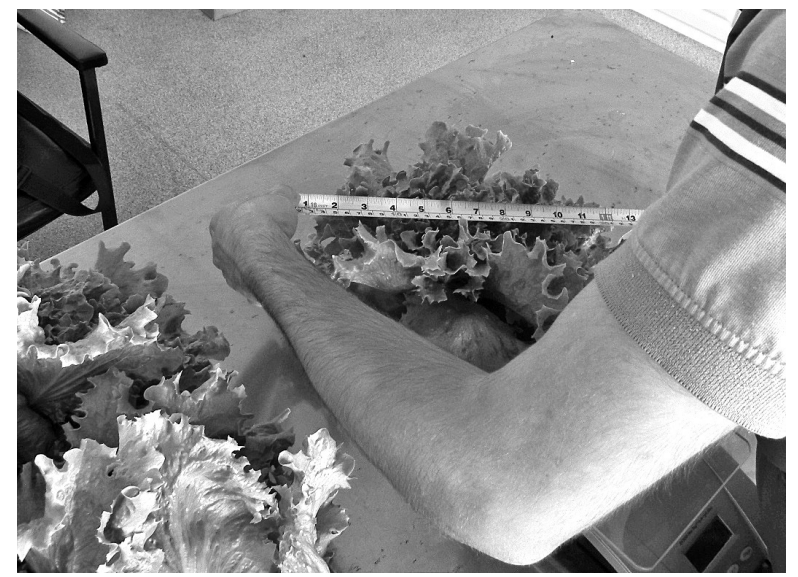

Figura 7. Medición del diámetro. Fuente: las autoras.

Cuadro 2. Descripción de las observaciones en cada ensayo ejecutado en el 2013.

\begin{tabular}{|c|c|}
\hline Ensayo & Observaciones \\
\hline I & $\begin{array}{l}\text { Se lavó con agua y jabón el reservorio y los tubos. Se adquirió el almácigo en edad para trasplante. Se desinfectó } \\
\text { sumergiendo las raíces en una solución de peróxido de hidrógeno al } 1 \% \text { por } 2 \text { segundos y se trasplantaron a las } \\
\text { canastillas con piedra volcánica desinfectada. Se usaron canastillas tradicionales para NFT (véase figura 2) en la cama } \\
\text { I para sostener las lechugas en las aperturas de los tubos, y vasos plásticos (tipo vajilla desechable, véase figura 3) } \\
\text { con ranuras en la cama } 2 \text {. Se activó el protocolo de buenas prácticas para el ingreso y salida del invernadero. Se } \\
\text { dejaron las plantas con el sistema de recirculación activado, con agua únicamente, por } 24 \text { horas, con un tiempo de } \\
\text { circulación de } 45 \text { minutos y } 15 \text { minutos en reposo. Igualmente, se colocó la cobertura de sarán. Luego, se adicionó } \\
2,5 \mathrm{ml} / \mathrm{I} \text { de agua total en el sistema de la solución nutritiva A, y Iml/I de agua total en el sistema de la solución } \\
\text { nutritiva B. Se reguló el tiempo de encendido y apagado de la bomba a } 30 \text { minutos en circulación y } 30 \text { minutos } \\
\text { en reposo. Las plantas presentaron decaimiento general y raíces oscurecidas a los I } 5 \text { días después de trasplante, } \\
\text { por lo que se aplicó Trichoderma sp + Streptomyces sp a la solución nutritiva y se empezó a eliminar las plantas } \\
\text { enfermas. A los } 35 \text { días se retiró la cobertura del sarán. Se obtuvo un rendimiento en cosecha del } 36 \% \text { en la cama } \\
\text { I, y del } 0,75 \% \text { en la cama } 2 \text {. }\end{array}$ \\
\hline
\end{tabular}




\begin{tabular}{|c|c|}
\hline Ensayo & Observaciones \\
\hline 2 & $\begin{array}{l}\text { Se lavó con agua y jabón el reservorio y los tubos. Se adquirió el almácigo en edad para trasplante. El mismo } \\
\text { se desinfectó sumergiendo las raíces en una solución de peróxido de hidrógeno al I\% por } 2 \text { segundos y se } \\
\text { trasplantaron a las canastillas con piedra volcánica desinfectada, sin seguir estrictamente el protocolo planteado } \\
\text { inicialmente. Se usaron canastillas tradicionales para NFT para ambas camas. También, se colocó la cobertura de } \\
\text { sarán. Se activó el protocolo de Buenas Prácticas para el ingreso y salida del invernadero. Se dejaron las plantas con } \\
\text { el sistema de recirculación activado, con agua únicamente, por } 24 \text { horas, con un tiempo de circulación de } 45 \text { minutos } \\
\text { y I } 5 \text { minutos en reposo. Luego, se adicionó } 2,5 \mathrm{ml} / \mathrm{I} \text { de agua total en el sistema de la solución nutritiva A, y Iml/l de } \\
\text { agua total en el sistema de la solución nutritiva B. Se reguló el tiempo de encendido y apagado de la bomba a } 30 \\
\text { minutos en circulación y } 30 \text { minutos en reposo. A los I } 3 \text { días, se observan algunas raíces oscurecidas por lo que se } \\
\text { aplicó Trichoderma sp + Streptomyces sp a la solución nutritiva y se empezaron a eliminar plantas enfermas. A los } \\
23 \text { días se retiró la cubierta del sarán y el problema radicular empeoró, además las hojas mostraron marchitez y } \\
\text { amarillamiento. A los } 30 \text { días se determinó que el estado de las plantas era irreversible y se eliminaron, dando un } \\
\text { rendimiento de } 0 \% \text { de cosecha. }\end{array}$ \\
\hline 3 & $\begin{array}{l}\text { Se desinfectaron con cloro y peróxido el reservorio y los tubos. Se adquirió el almácigo en edad para trasplante. El } \\
\text { mismo se desinfectó sumergiendo las raíces en una solución de peróxido de hidrógeno al I\% por } 2 \text { segundos y se } \\
\text { trasplantaron a las canastillas tradicionales para NFT con piedra volcánica desinfectada, sin seguir estrictamente el } \\
\text { protocolo planteado inicialmente. Se activó el protocolo de buenas prácticas para el ingreso y salida del invernadero } \\
\text { sin verificar que este se cumpliera el } 100 \% \text { del tiempo. También se colocó la cobertura de sarán. Se dejaron las } \\
\text { plantas con el sistema de recirculación activado, con agua únicamente, por } 24 \text { horas, con un tiempo de circulación } \\
\text { de } 45 \text { minutos y I } 5 \text { minutos en reposo. Luego se adicionó } 2,5 \mathrm{ml} / / \text { de agua total en el sistema de la solución nutritiva } \\
\text { A, y I ml/l de agua total en el sistema de la solución nutritiva B. Se reguló el tiempo de encendido y apagado de } \\
\text { la bomba a } 30 \text { minutos en circulación y } 30 \text { minutos en reposo. Al día } 8 \text {, se observó daño foliar por hongo y por } \\
\text { cortador, por lo que se aplicó Trichoderma sp foliar a las plantas, y cuatro días después Chilagro y Beauveria sp y } \\
\text { Metarhizium sp. A los I } 5 \text { días después de trasplante, se adicionó Trichoderma sp, Streptomices sp y Pseudonoma } \\
\text { fluorescens a la solución nutritiva. Se registró un aumento en el la escala de pH de la solución y se intentó regularlo } \\
\text { con una fuente natural: jugo de limón, sin embargo la dosis aplicada generó un cambio de pH drástico. Las raíces } \\
\text { siguieron un proceso de necrosis y las plantas mostraron marchitez permanente, por lo que se eliminaron al día } 28 . \\
\text { Se obtuvo un } 0 \% \text { de rendimiento de la cosecha. }\end{array}$ \\
\hline 4 & 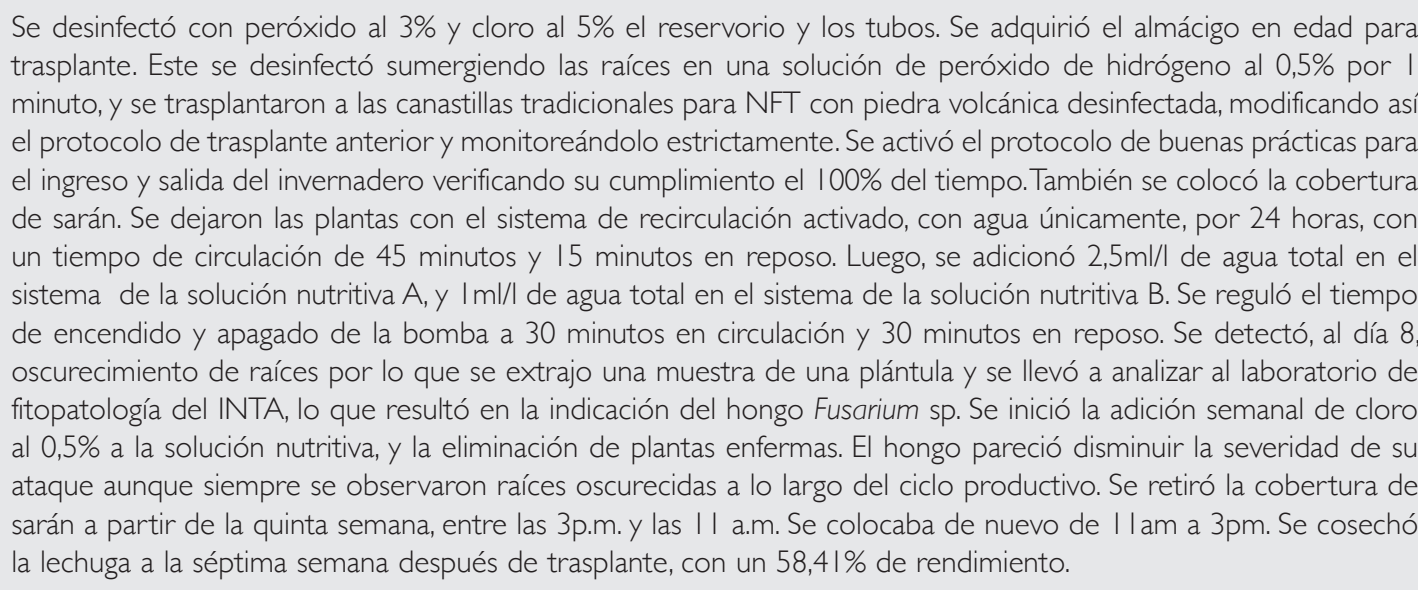 \\
\hline 5 & $\begin{array}{l}\text { En desarrollo, a la fecha. Se desinfectó con peróxido al } 3 \% \text { y cloro al } 5 \% \text { el reservorio y los tubos. Se adquirió } \\
\text { el almácigo en edad para trasplante, esta vez con un sustrato tipo "peat moss". Este se desinfectó sumergiendo } \\
\text { las raíces en una solución de peróxido de hidrógeno al } 0,5 \% \text { por I minuto y se trasplantaron a las canastillas } \\
\text { tradicionales. Se activó el protocolo de buenas prácticas para el ingreso y salida del invernadero. También, se colocó } \\
\text { la cobertura de sarán. Se dejaron las plantas con el sistema de recirculación activado, con agua únicamente, por } \\
24 \text { horas, con un tiempo de circulación de } 45 \text { minutos y } 15 \text { minutos en reposo. Luego, se adicionó } 2,5 \mathrm{ml} / \mathrm{l} \text { de agua } \\
\text { total en el sistema de la solución nutritiva A, y I ml/I de agua total en el sistema de la solución nutritiva B. Se reguló } \\
\text { el tiempo de encendido y apagado de la bomba a } 30 \text { minutos en circulación y } 30 \text { minutos en reposo. Se detectó, al } \\
\text { día } 8 \text {, oscurecimiento de raíces, considerado nuevamente un síntoma de Fusarium sp, por lo que se inició la adición } \\
\text { semanal de cloro al 0,5\% a la solución nutritiva, y la aplicación de un fungicida, tiabendazol, según recomendación } \\
\text { de laboratorio de fitoprotección del INTA. Estees sistémico de amplio espectro, en dosis recomendadas para drench } \\
\text { en suelo (no hay registro de uso en hidroponía NFT por parte del proveedor). }\end{array}$ \\
\hline
\end{tabular}




\section{Conclusiones y recomendaciones}

Los protocolos de desinfección, de seguimiento y control, y cosecha son críticos y determinantes en el rendimiento de producción pues podrán relacionarse a la inserción de patógenos o cambios en condiciones fisicoquímicas del sistema que afectan el desarrollo de las plantas.

El origen del almácigo pudo insertar el patógeno Fusarium sp, que se encuentra alojado actualmente en el sistema, lo que demuestra que el protocolo de desinfección de almácigo y sistema pudo ser violentado $y$, por tanto, haber permitido el ingreso del mismo.

En los casos de los protocolos de seguimiento y control, particularmente el tema de ingreso a invernadero es clave en la incidencia de enfermedades $y$, sobre todo, plagas que logran ingresar al invernadero y causar daños en las plantas. De haber fallos en este aspecto, y resultan en el ingreso de una plaga al medio, debe recurrirse al tratamiento de dicha plaga, generando posiblemente mayores costos de producción y atenciones adicionales al tema de retiro de productos antes de la cosecha de las hortalizas en caso que se trate de agroquímicos.
Nota I: Se contó con la valiosa colaboración, durante esta actividad de fortalecimiento, en cuanto a la recopilación y tratamiento de datos de los estudiantes asistentes Federico Gómez Coto y Álvaro Sáenz Guevara.

Nota 2: También se contó con el aporte del asistente administrativo Bernardo Quesada Sandoval y del profesor Ing. Luis Fernando Campos Meléndez, M.Sc.

\section{Bibliografía}

Barbado, J. (2005). Hidroponía. Buenos Aires, República Argentina: Albatros Saci.: http://books.google.co.cr/books?id=aa4A0Ga kMRsC\&printsec=frontcover\&dq=hidroponia\&hl=es\&ei=a bJwT7axBoyTtwew luicBg\&sa=

Brenes, L. (2010). Análisis Multicriterio de sistemas de producción de lechuga. Costa Rica: Curso Tópicos Avanzados de Gerencia y Gestión Ambiental. Maestría en Gerencia y Gestión Ambiental. Centro Interamericano de Posgrados.

Gómez Coto, F. y Sáenz Guevara, Á. (2013). Informe de labores de asistencia en proyecto TEC-VIE Sistema de producción de hortalizas hidropónicas tipo NFT. Cartago, Costa Rica.

González, R. (2008). Hidroponía en NFT. Recuperado el 26 de Marzo de 2012, de Boletín del Programa Nacional Sectorial de Producción Agrícola Bajo Ambientes Protegidos: http:// www.mag.go.cr/bibliotecavirtual/BoletinAP2( I 0).pdf 